\title{
"Colocando miçangas na guia": O pesquisar em saúde nos terreiros de Umbanda
}

\author{
"Putting the beads on necklaces": \\ The health research in the Umbanda terreiros
}

\author{
"Colocando las perlas en el collar": \\ El buscar en salud en terreros de Umbanda
}

\author{
Matheus Barbosa da Rocha ${ }^{2}$ \\ Ana Kalliny de Sousa Severo ${ }^{3}$ \\ Antônio Vladimir Félix da Silva ${ }^{4}$
}

\begin{abstract}
Resumo: O campo da saúde historicamente tem possibilitado pouca participação dos povos de terreiros tanto das suas práticas de planejamento, implementação, avaliação e gestão do cuidado em saúde como também das suas atividades de pesquisa. O presente artigo tem como objetivo discutir as estratégias metodológicas, e também os desafios na execução, de uma pesquisa realizada em três terreiros de Umbanda da cidade do interior do Piauí e nas consequentes Equipes de Saúde da Família que fazem cobertura dos referidos estabelecimentos sagrados. Pretende-se, com esse estudo, que a partir do compartilhamento de uma experiência investigativa contrária às perspectivas que sustentam a ideia do "pesquisador-perito", sejam estabelecidos diretrizes a futuros acadêmicos e pesquisadores do campo da saúde que se proponham em realizar estudos em terreiros de Umbanda.
\end{abstract}

Palavras-chave: Terreiros. Produção do conhecimento. Saúde.

Abstract: The field of health has historically allowed little participation of the peoples of terreiros both from their practices of planning, implementing, evaluating and managing health care as well as from their research activities. The present article aims to discuss the methodological strategies and also the challenges in the execution of a research carried out in three terreiros of Umbanda in the city of interior of Piauí and in the consequent Family Health Strategies that cover these sacred establishments. With this study, it is intended that from the sharing of an investigative experience contrary to the perspectives that underpin the idea of the "researcher-expert", guidelines should be established for future academics and researchers in the field of health who intend to carry out studies in terreiros of Umbanda.

Keywords: Terreiros. Knowledge production. Health.

Resumen: El campo de la salud históricamente ha posibilitado poca participación de los pueblos de terreros tanto de sus prácticas de planificación, implementación, evaluación y gestión del cuidado en salud así como de sus actividades de investigación. El presente artículo tiene como objetivo discutir las estrategias metodológicas, y también los desafíos en la ejecución, de una investigación realizada en tres terreiros de Umbanda de la ciudad del interior del Piauí y en las consecuentes Estrategias de Salud de la Familia que cubren los referidos establecimientos sagrados. Pretendemos, con ese estudio, que a partir del compartir una experiencia investigativa contraria a las perspectivas que sustentan la idea del "investigador-perito", se establezcan directrices a futuros académicos e investigadores del campo de la salud que se propongan realizar estudios en terreiros Umbanda.

Palabras clave: Terreiros. Producción del conocimiento. Salud.

\footnotetext{
${ }^{1}$ Submetido em: 19 dez. 2019 - Aceito em: 16 maio 2019 - Publicado em: 06 set. 2019.

${ }^{2}$ Universidade Federal do Piauí (UFPI) - E-mail: matheusbr.psico@live.com

${ }^{3}$ Universidade Federal do Rio Grande do Norte (UFRN) - E-mail: kallinysevero@yahoo.com.br

${ }^{4}$ Universidade Federal do Piauí (UFPI) - E-mail: wladyfelix@ hotmail.com
} 


\section{Introdução}

Esse artigo parte do pressuposto de que o ato de confeccionar uma guia ${ }^{\mathrm{i}}$ e o de pesquisar em saúde nos terreiros são processos similares. Para contextualizar a construção da nossa guia investigativa, utilizamos como direcionador a experiência referente a uma pesquisa de mestrado intitulada "Nos Batuques dos Quintais: As interfaces do cuidado em saúde entre religiões de terreiros e Equipes de Saúde da Família (ESF)”. No caso desse texto, tanto o ato de fazer uma guia como o de investigar processos referentes às religiões afrobrasileiras nos levam para um mesmo lugar, os terreiros. Assim como os praticantes dessas doutrinas, nós também sentamos, pegamos uma linha e de conta em conta fizemos nossa guia.

Desse modo, um primeiro elemento importante de ressaltarmos diz respeito ao fato de que o continente africano era composto por diversas nações, cada uma com suas próprias etnias, costumes, crenças e tecnologias. Com a chegada dos portugueses na região, estes terminaram por se aproveitar do modo de organização tribal instituído pela população nativa, objetivando incentivar guerras entre os diferentes grupos. Os vencidos eram colocados à venda ou trocados com os europeus por produtos necessários e apreciados pelos africanos, como sal e cachaça (BARROS, 2009).

Com essa artimanha, os portugueses pretendiam utilizar o trabalho destes povos como mão de obra escravizada nas usinas de cana-de-açúcar do Nordeste brasileiro. Posteriormente, com o passar dos séculos, também vieram a instituir o trabalho de tais sujeitos tanto nos garimpos de ouro de Minas Gerais quanto nas lavouras de café, localizadas nos interiores de São Paulo e Rio de Janeiro. Para chegar ao Brasil, esses povos eram exportados aos montes em navios cargueiros, conhecidos por possuírem insalubres condições para se viver, o que culminava em uma dizimação dos negros já durante a viagem.

Ao chegarem ao Brasil, os negros se depararam com uma sociedade instituída pelo teor aristocrata e escravista, atribuindo àqueles oriundos da África um valor mercadológico de compra e venda, assim como qualquer outro produto. Para legitimar seu poder, tal sistema fazia uso da coerção, bem como da violência física, psicológica e de diversos outros tipos de humilhação (CASTRO, 2012). Desse modo, eram frequentes situações em que os chamados "capitães do mato"ii açoitavam em um tronco os escravizados fugitivos ou desobedientes.

É preciso ressaltarmos que quando estes chegaram ao Brasil, a responsabilidade de catequizá-los passou a ser de seus donos. Com isso, instituiu-se um processo de educação religiosa em que os "senhores de engenho" se responsabilizavam pela iniciação cristã dos escravos sob sua tutela. Entretanto, precisamos reconhecer que esse procedimento não era um dos mais exigentes, visto que para ser considerado católico bastava o negro responder algumas questões (RIBEIRO, 2012), algo que uma ou duas chicotadas muito bem resolveria.

Em decorrência deste e de outros fatores, os sujeitos escravizados organizaram uma série de movimentos instituintes contra essa dominação, como fugas, boicotes ao trabalho, organizações de quilombos e preservação dos seus principais elementos culturais, tais como dialetos, cantigas, danças e religiões, contudo, estas muito comumente passaram a se instituir 
de modo camuflado, como, por exemplo, as divindades africanas travestidas de santos católicos, questões estas que foram de fundamental importância na constituição das religiões afro-brasileiras, em especial da Umbanda (FREITAS, 2012), religião sobre a qual lançamos olhares aprofundados.

Além disso, problemáticas então instituídas na sociedade brasileira, como a ineficiência e o descaso dos tratamentos médicos durante o governo imperial também foram elementos definidores no desbocamento destas práticas sagradas (LAGES, 2012), momentos nos quais além de cultuarem os Orixás e os espíritos antepassados, também ofertavam práticas de cuidado em saúde para questões de ordem física, psicológica, espiritual ou problemas do cotidiano (SILVEIRA, 2014).

Desse modo, podemos perceber que apesar do Brasil ser constituído em sua maioria por fiéis, declaradamente, da Igreja Católica, sempre foram infindáveis os casos de cuidado em saúde ofertados por centros espíritas ou terreiros de religiões de matrizes africanas, em decorrência de encomendas como doenças, desempregos ou amores mal resolvidos. Acreditamos, portanto, que os líderes religiosos de tais crenças historicamente têm sido procurados para lidar com os mesmos sintomas trabalhados, em determinadas circunstâncias, pelos profissionais da saúde (MELLO; OLIVEIRA, 2013).

Ao tomarmos como pressupostos, alguns marcos legais, como as leis complementares $\mathrm{n}^{\circ} 8.080$ (BRASIL, 1990a) e $\mathrm{n}^{\circ} 8.142$ (BRASIL, 1990b), o princípio da Equidade, os três primeiros Planos Nacionais de Direitos Humanos (PNDH 1, 2 e 3) (ADORNO, 2010), o documento "Subsídios para o Debate sobre a Política Nacional de Saúde da População Negra: Uma Questão de Equidade" (BRASIL, 2001), o decreto $\mathrm{n}^{0}$ 6.872, de junho de $2009^{\text {iii }}$ (BRASIL, 2009), a Política Nacional de Saúde Integral da População Negra (PNSIPN) (BRASIL, 2013a), a lei $\mathrm{n}^{\circ}$ 12.228, de 20 de julho de 2010 ${ }^{\text {iv }}$ (BRASIL, 2010) e a Política Nacional de Educação Popular em Saúde (PNEPS-SUS) (BRASIL, 2013b), percebemos ser de suma importância que os profissionais de saúde estabeleçam interfaces nas ofertas de cuidado em saúde com os aspectos simbólico-culturais concernentes à população negra, como é o caso das religiões de terreiros, e, de modo mais específico, a Umbanda.

Entretanto, o que historicamente temos assistido é uma tentativa de uma reduzida participação desses atores sociais tanto na micropolítica do trabalho vivo como também enquanto sujeitos participantes das ações de planejamento, implementação e avaliação de políticas públicas que, em maior ou menor medida, lhes sejam específicas. No campo da pesquisa em saúde, essa realidade não é muito diferente, já que ainda têm sido bastante incipientes as pesquisas realizadas por profissionais e pesquisadores do campo da saúde sobre as práticas de cuidado em saúde nos terreiros de religiões afro-brasileiras.

Uma das primeiras investigações realizada por acadêmicos e profissionais do campo da saúde sobre o assunto foi conduzida por Gomes (2010) com objetivo de relatar uma experiência de institucionalização de um estabelecimento de saúde dentro de um terreiro de Candomblé. A proposta de criação do posto sanitário surgiu em decorrência da necessidade do sistema de saúde local melhorar o acesso e a qualidade da atenção à saúde prestada a um grupo particular de mulheres, que em sua maioria eram negras $(52,3 \%)$, possuíam ensino fundamental incompleto $(36,9 \%)$ e estavam vinculadas ao Candomblé. 
Outra pesquisa que também versou sobre as possíveis interfaces entre estabelecimentos de saúde e terreiros foi a pesquisa realizada por Mota e Trad (2011) que se propôs a estudar o Candomblé como um espaço de produção de práticas/sentidos em torno dos processos de saúde-cura-adoecimento. Apesar do texto discorrer majoritariamente sobre as doenças físicas, psicológicas ou espirituais e as consequentes práticas de cuidado em saúde dos terreiros para acolhê-las ou curá-las, também são trazidas discussões sobre os possíveis itinerários terapêuticos dos consulentes.

No ano de 2013, mais dois estudos sobre a temática foram realizados. O primeiro, de Mello e Oliveira (2013), teve como intuito principal discorrer sobre a complementaridade existente entre o sistema de saúde oficial e as terapêuticas religiosas afro-brasileiras, considerando as formas como as pessoas vivenciam e interpretam a doença, o sofrimento, a dor e as práticas de cura.

Ainda no ano de 2013, Rios e colaboradores (2013) conduziram um estudo que pretendia compreender como se desenrolava o engajamento de terreiros de religiões de matrizes africanas da região metropolitana do Recife na prevenção do HIV/Aids, considerando sua estrutura simbólica. Segundo essa investigação, os pesquisadores puderam identificar a realização de atividades instituintes envolvendo pais e mães de santos, antropólogos e técnicos da Coordenação Estadual de DST/Aids da Secretaria de Saúde de Pernambuco.

Por fim, em 2017, assistimos à realização de um estudo sob a condução de Silva, Fernandez e Sacardo (2017), os quais objetivaram investigar as conversações estabelecidas já instituídas entre serviços de saúde e terreiros. Para alcançar esse objetivo, os referidos autores construíram três categorias para explicar as diferentes modalidades de interações: como alternativa ou como complemento à medicina hegemônica e como uma terapêutica que possui potências e singularidades que lhes são específicas.

A partir desses estudos, podemos perceber o quanto ainda são incipientes as investigações em saúde nos estabelecimentos religiosos de matrizes africanas, sendo, portanto, necessário o compartilhamento de experiências investigativas que sejam realizadas nesses contextos, visto que, a partir disso, é possível que criemos diretrizes de pesquisa a acadêmicos e profissionais do campo da saúde que se proponham em investigar questões sociais, econômicas, políticas e culturais relacionadas aos terreiros de religiões afrobrasileiras.

O presente artigo tem como objetivo discutir as estratégias metodológicas adotadas em uma pesquisa realizada em três terreiros de Umbanda da cidade do interior do Piauí e nas consequentes ESF que faziam cobertura dos referidos estabelecimentos sagrados. Além disso, também ambicionamos compartilhar as dificuldades vivenciadas durante nosso percurso investigativo, procurando, a partir disso, refletir sobre os desafios enfrentados quando pesquisadores se propõem a realizar estudos nesses contextos. 


\section{Desenvolvimento}

Para confecção da nossa guia, num primeiro momento, foi preciso que embarcássemos na literatura, a fim de que compreendêssemos nosso campo de pesquisa, de modo a estabelecer uma pergunta de partida e os objetivos que nos sustentariam. Essa busca nos levou aos autores que mencionamos em nossa seção anterior e, a partir deles, foi estabelecido que estudaríamos as interfaces do cuidado em saúde entre religiões de terreiros e ESF.

De modo mais específico, nossa ambição consistiu em: (1) conhecer as concepções dos praticantes e consulentes das religiões de terreiros sobre saúde, adoecimento e cuidado em saúde; (2) mapear os processos de cuidado em saúde promovidos pelas religiões afrobrasileiras direcionados aos seus praticantes, consulentes e à comunidade de forma geral; e (3) caracterizar as estratégias de cuidado em saúde desenvolvidas pelas ESF em relação aos povos de terreiro.

Uma vez tendo sido estabelecido uma pergunta de partida e objetivos que pudessem nos direcionar em nossa peregrinação, surgiu uma preocupação: a de não desenvolvermos, enquanto pesquisadores, relações colonizadoras do saber, onde simplesmente chegaríamos, colheríamos informações e depois iríamos embora. Desse modo, foi tomando como pressuposto esse fio ético-político que fomos tecendo a guia que nos acompanhou durante nossa pesquisa nos terreiros de Umbanda e nas ESF.

Por conta disso, a primeira miçanga a escolhermos consistiu na Análise Institucional de René Lourau e Georges Lapassade como matriz de investigação e como estratégia de produção e análise das informações. No contexto da Saúde Coletiva, a Análise Institucional acaba se mostrando como uma estratégia rica e potente para o desenvolvimento de investigações que não pretendam apenas verificar leis e regularidades a partir de proposições rigorosas e específicas, mas também almejem olhar para seu objeto de investigação a partir de suas particularidades, de modo a tensioná-lo junto a proposições que longe de nos aprisionar, também nos possibilite "linhas de fuga" às perspectivas pragmáticas e positivistas de se fazer ciência (L'ABBATE, 2003). Nessa proposta investigativa, o intuito é "transformar para conhecer" e não o seu contrário, como geralmente é proposto pelas várias correntes das Ciências Sociais (L’ABBATE, 2013).

Desse modo, podemos concluir que o intuito principal da Análise Institucional é compreender a realidade social e organizacional dos sujeitos com base em suas declarações e também nas suas práticas desenvolvidas (SPAGNOL et al., 2016), de modo a deflagrar os processos auto-analíticos e autogestivos dos coletivos sociais (BAREMBLITT, 2002). Dentro desse escopo, como linha para nossa guia, fizemos uso da Análise Institucional "no Papel".

Essa premissa se caracteriza como um método de conhecimento e de práticas em que se objetiva realizar uma análise econômica, política, funcional, estrutural e estruturofuncional dos processos sociais que nos circundam (LOURAU, 1975). Nessas modalidades de pesquisa, um conceito importante é o de analisador, compreendido como aquilo que nos 
permite provocar os conteúdos outrora implícitos das instituições, fazendo-os ver e falar (LOURAU, 2004).

Uma vez escolhida essas questões basilares, fomos em busca de miçangas que nos possibilitasse organizar como se configuraria nossa imersão no campo de pesquisa. Assim, a segunda das miçangas consistiu nos locais em que realizamos o estudo, que aconteceu em seis locais distintos, mais especificamente em três terreiros de Umbanda da cidade do interior do Piauí, bem como nas ESF correspondentes aos territórios em que os referidos estabelecimentos religiosos estavam inseridos durante a ocasião do estudo.

A seleção desses três terreiros aconteceu de acordo com conveniências pessoais, isto é, não obedeceram a qualquer espécie de critérios previamente definidos. Em linhas gerais, o processo se desenrolou do seguinte modo: utilizando como intermediários alguns amigos envolvidos com as religiões afro-brasileiras, entramos em contato com as lideranças religiosas e, a partir delas, com os centros espíritas propriamente ditos. Uma vez selecionados os terreiros, buscamos identificar quais ESF faziam cobertura do território em que se localizavam as instâncias religiosas em questão.

As regiões em que se encontram as casas espirituais investigadas guardavam algumas semelhanças entre si. A primeira delas diz respeito ao fato dos bairros estarem localizados em regiões consideradas "antigas" da cidade: enquanto dois deles tiveram suas origens nos arredores da Colônia do Carpina, mais conhecida anteriormente como leprosário, o outro surgiu em virtude de um programa de distribuição de casas populares realizado pelo então governador do estado.

Além disso, outras características apresentadas pelas regiões em que esses estabelecimentos estavam localizados eram as seguintes: altos níveis de violência urbana; péssimas condições de infraestrutura, tais como calçamentos quebrados, algumas ruas de areia e uma ínfima quantidade de postes com iluminação noturna; e dificuldade no acesso às essas regiões, principalmente em virtude dos poucos transportes públicos que faziam rotas até os respectivos bairros, problemática esta que se confunde com uma situação crônica que atravessa a própria cidade em estudo, já que o município em questão não possui (pelo menos até a realização dessa pesquisa) uma empresa fixa de ônibus, mas, tão somente, uma cooperativa de motoristas de micro-ônibus, que dificilmente circulam durante o período da noite e aos finais de semana.

No que concerne à caracterização dos terreiros umbandistas pesquisados, é importante ressaltarmos que duas das casas espirituais eram conduzidas por mulheres (Ashanti e Mmaabo). Ambas eram negras, tinham aproximadamente 60 anos de idade e realizavam suas atividades espirituais em salões construídos nos quintais das suas próprias residências.

Ao contrário delas, o terceiro centro se autointitulava como uma casa espiritual que adotava como princípios os ensinamentos de várias filosofias e doutrinas religiosas. Entretanto, suas cerimônias e rituais sagrados seguiam as tradições umbandistas, já que as divindades cultuadas nesse espaço pertenciam à referida religião. Entretanto, caso fosse preciso, eles agregavam elementos de outras crenças também em seus cultos, como por exemplo, alguma cantiga católica que considerassem bonita e com uma mensagem positiva. 
Além dos fatos já mencionados, o centro religioso em questão também possuía como características principais o fato de funcionar em um espaço alugado exclusivamente para essa função (e não na residência do líder da casa, como comumente acontecia), além de ser conduzido por um homem (Azekel) de aproximadamente 45 anos de idade. Enquanto nos dois primeiros casos, as referidas mulheres se apresentavam como "mães de santo", no outro, o condutor se intitulava como "dirigente da casa".

Uma vez tendo escolhido a pergunta de partida, a matriz teórico-metodológica e os locais de pesquisa, foi preciso nos dedicarmos a outra conta de grande importância na construção de uma guia: os participantes. Os sujeitos que compuseram este estudo estavam divididos em três grupos. No primeiro deles, tivemos três líderes de terreiros de Umbanda, mais especificamente duas mulheres e um homem, os quais nomeamos ficticiamente como Ashanti, Mmaabo e Azekel.

O segundo grupo era composto pelos praticantes e pelos consulentes dos mesmos terreiros conduzidos pelas lideranças religiosas anteriormente mencionadas. Apesar de não ter uma estimativa exata sobre a quantidade de praticantes e consulentes com quem conversamos em cada estabelecimento religioso, já que tais diálogos se desenrolaram durante nossa imersão no campo de pesquisa, uma estimativa aproximada possa ser a seguinte: 10 consulentes e 03 praticantes no terreiro de Mmaabo e 05 consulentes e 03 praticantes no de Azekel. Em decorrência do modo como se configuravam as cerimônias de cuidado em saúde do centro espírita de Ashanti, o contato com os praticantes e consulentes do referido estabelecimento terminou sendo bastante escasso. O terceiro coletivo foi composto pelos profissionais de três ESF (ESF 1 - 11 pessoas; ESF 2 - 12 pessoas; ESF 3 - 9 pessoas).

Na quarta miçanga, definimos os instrumentos que nos possibilitariam ir ao campo de intervenção. Em decorrência do fato de, na ocasião da presente investigação, não querermos nos apresentar enquanto pesquisadores-peritos, os quais se caracterizam por não mergulharem na realidade/cotidiano do território em estudo e, por conta disso, pouco dialogarem com as necessidades psicossociais dos sujeitos que habitam os espaços de pesquisa, optamos por nos utilizar dos seguintes instrumentais: observação participante das cerimônias religiosas em que as casas espirituais conduzidas por esses sujeitos ofertavam espaços de cura, cuidado em saúde, aconselhamento e orientação espiritual à população de forma geral; e conversas informais com os praticantes e consulentes dos respectivos estabelecimentos sagrados durante nossas imersões.

Além disso, por acreditarmos que os líderes desses estabelecimentos religiosos carregam consigo uma gigantesca bagagem cultural, intelectual e afetiva sobre as respectivas simbologias, crenças e concepções de cuidado em saúde das religiões afro-brasileiras, em especial da Umbanda, percebemos a necessidade de se reservar alguns momentos para conversar particularmente com essas figuras-chave. Por conta disso, realizamos entrevistas semiestruturadas com os três condutores dos terreiros em questão.

Paralelo a isso, foram conduzidas uma roda de conversa com cada ESF. De modo geral, essa tecnologia é bastante útil no contexto de pesquisas interventivas, já que possibilita a criação de espaços de diálogos, possibilitando uma valorização das experiências dos participantes. Há uma horizontalização das relações de poder, de modo que se dissolve a 
figura do mestre como centro do processo e, em vez disso, emerge a fala como signo de valores, normas, cultura, práticas e discursos (SAMPAIO et al., 2014).

Com todos esses elementos definidos, partimos para um mergulho em nosso campo de intervenção, imersão esta que obedeceu alguns passos, os quais foram estabelecidos na quinta miçanga dessa guia, os procedimentos. A princípio, após aprovação da pesquisa no Comitê de Ética e Pesquisa (CEP), da Universidade Federal do Piauí (UFPI), Campus Ministro Petrônio Portela, sob o CAAE $n^{\circ}$ 79267617.7.0000.5214, entramos em contato com as três lideranças religiosas do estudo em questão. Conforme mencionamos anteriormente, não estabelecemos nenhuma espécie de critério para que pudéssemos escolher os referidos terreiros.

E isso transcorreu por conta de uma justificativa. Ainda são inexistentes, no âmbito municipal, investigações que se proponham mapear quantitativamente aspectos sociais, econômicos, políticos e culturais em que os centros religiosos afro-brasileiros do município em questão estão circunscritos, tais como: quantidade de terreiros e a concentração dos mesmos na cidade; características dos imóveis (próprios ou alugados) e dos terreiros (extensão da residência do condutor ou não); tipos de cerimônias de festejo às divindades e também de cuidado em saúde; escolaridade, religião e renda financeira dos adeptos e consulentes, dentre outras questões.

Por conta disso, percebemos que ao tentar estabelecer qualquer critério de elegibilidade para selecionar os terreiros do estudo, seria necessário que possuíssemos algumas informações primordiais no que concerne a pelo menos uma pequena parcela dos estabelecimentos religiosos afro-brasileiros da cidade. Como isso não aconteceu, a seleção dos mesmos se configurou por meio de indicações de amigos que tinham alguma proximidade com as religiões de matrizes africanas, em especial, com a Umbanda.

Num primeiro momento, como forma de estabelecer um contato inicial, realizamos as entrevistas semiestruturadas com as lideranças religiosas. Em seguida, fomos nos inserindo, por meio da observação participante e das conversas informais, nas cerimônias de oferta de cuidado em saúde à comunidade, entretanto, em decorrência do fato de que cada terreiro organizava essas atividades de um modo distinto, uma consequência foi a de que terminamos nos inserindo em quantidades diferentes de visitas em cada estabelecimento religioso, conforme podemos visualizar no Quadro 1 - Atendimentos em Saúde nos Terreiros Investigados.

Quadro 1. Atendimentos em Saúde nos Terreiros Investigados

\begin{tabular}{|c|c|c|}
\hline Terreiros & Funcionamento & Imersão \\
\hline Ashanti & $\begin{array}{c}\text { Consulente é atendido a qualquer momento que } \\
\text { chegue independente do dia e horário }\end{array}$ & $\begin{array}{c}\text { Não acompanhamos os } \\
\text { atendimentos }\end{array}$ \\
\hline Mmaabo & Três vezes por semana no horário da tarde & Oito Visitas \\
\hline Azekel & Uma vez por semana (três vezes por mês) & Três Visitas \\
\hline
\end{tabular}

Fonte: Elaborado pelos autores.

Paralelo a esse processo, também realizamos uma roda de conversa com as ESF referentes a cada terreiro de Umbanda investigado. Entramos em contato com as mesmas 
após nossas primeiras visitas aos estabelecimentos religiosos em questão, circunstância em que as entrevistas semiestruturadas com as três lideranças religiosas já haviam possibilitado as primeiras conversações com os povos de terreiros.

Após escolhidas todas essas miçangas, foi preciso selecionarmos a última, aquela que daria beleza e encanto ao nosso artefato: trata-se das análises dos dados. Para isso, é importante ressaltarmos que as entrevistas com as lideranças religiosas foram gravadas e, posteriormente transcritas na íntegra, sendo que isso não foi possível em apenas um local, visto que o centro religioso do qual o sujeito fazia parte não autorizava gravações ou filmagens dentro do referido espaço. Assim, no caso em questão, realizamos anotações durante toda nossa conversação, mesma estratégia que adotamos na realização das conversas informais e das rodas de conversas.

Ao final de todos os encontros, fossem eles para fazer alguma entrevista semiestruturada com os condutores dos centros religiosos afro-brasileiros, fosse para dialogar com os consulentes ou realizar rodas de conversas com os profissionais das ESF, armazenamos todas as conversações estabelecidas em diários de campos, espaços nos quais também registramos nossas percepções bem como os acontecimentos decorridos.

Em seguida, realizamos duas leituras a partir do material coletado: uma primeira, de identificação, em que nos familiarizamos com os discursos dos sujeitos entrevistados e dos membros dos grupos conduzidos; e uma segunda, com o intuito de descobrir as instituições que atravessavam os discursos dos participantes.

Diante desse cenário, fizemos uso de um conceito demasiadamente importante no que se refere às análises das informações pelo viés do institucionalismo francês. Trata-se do que denominamos como analisador, o qual explicitamos acima (LOURAU, 2004). É importante ressaltarmos que ao dissertar sobre nossa guia investigativa e a maneira como ela foi organizada (que pode ser visualizada com mais detalhes na Figura 1. Caminho Metodológico da Investigação) não significa que durante nossa peregrinação não enfrentamos percalços das mais diversas ordens.

Em primeiro lugar, imagine a seguinte situação. Você é psicólogo recém-ingresso num Programa de Pós-Graduação em Psicologia e se propõe em estudar as práticas de cuidado em saúde ofertadas em terreiros de Umbanda de uma cidade do litoral piauiense. Entretanto, na ocasião, uma série de questões o afligem. A principal delas dizia respeito ao fato de que sua família tinha bastante preconceito com as religiões de matrizes africanas.

Por conta disso, essas pessoas tentavam a todo custo impedir a realização do estudo, já que, na concepção das mesmas, esse rapaz estaria envolvido com práticas demoníacas. Por conta disso, alguns gritos e desentendimentos surgiram, de modo que, em determinados momentos, ele próprio questionou a necessidade e relevância do referido estudo.

Assim, por mais que a iniciativa de pesquisar as práticas de cuidado em saúde nos terreiros tenha surgido a partir do referido personagem, nas ocasiões em que o mesmo precisava mergulhar em seu campo de intervenção, sentimentos de medo e angústia costumavam o atravessar: quase sempre, saia à surdina, como se estivesse cometendo uma espécie de crime, pecado ou algo do gênero. 
Nos momentos em que o analista institucional se encontra em tão "maus lençóis", é necessário que sensibilize seu olhar para uma miçanga de grande importância na confecção de uma guia investigativa, a análise de implicação. É a partir dela ser possível perceber quais analisadores turvam nossas visões e compreender com maior nitidez o que Lourau (2004) denomina como sobreimplicação. Para o autor, esse fenômeno se desenrolaria nas situações em que nossos relacionamentos com os objetos/campos de pesquisa preenchem nossos tempos/espaços a tal ponto de esvaziar os outros campos de implicação existentes, tais como a encomenda, a demanda, a autoanálise, a autogestão e as relações com a teoria e com a escrita, conforme aconteceu no caso mencionado acima.

Figura 1. Caminho Metodológico da Investigação.

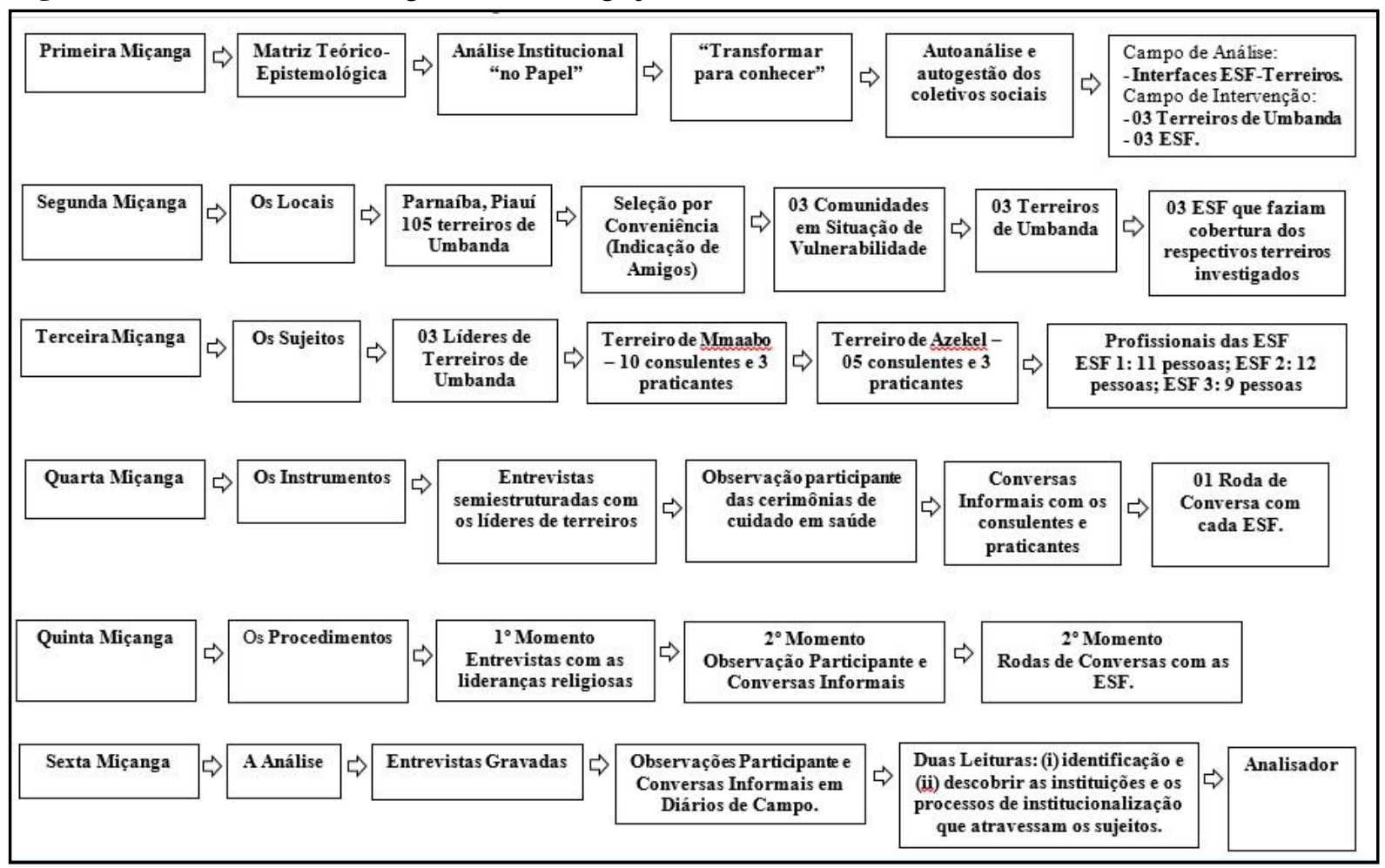

Fonte: Elaborado pelos autores.

Entretanto, engana-se quem pensa que essas situações de discriminação aos adeptos das religiões afro-brasileiras estiveram (e estão) presentes apenas no caso mencionado acima. Pelo contrário! Infelizmente, relatos de preconceito, intolerância e discriminação contra esses grupos religiosos se fizeram presentes na constituição da sociedade brasileira, de modo que os próprios pesquisadores do campo da saúde podem carregar consigo muitos estereótipos e preconceitos, em grande parte devido ao conservadorismo religioso e às doutrinas relacionadas ao catolicismo/protestantismo que constantemente nos atravessam.

O que podemos perceber, então, é que o racismo em muito permeia as instituições, organizações e estabelecimentos que nos circundam, as quais, na maioria das vezes, fracassam na tarefa de ofertar serviços apropriados e equitativos para os sujeitos-alvo de suas intervenções, de modo a não levar em consideração as questões étnico-raciais que os circunscrevem (KALCKMANN et al., 2007). 
Quando o racismo opera a nível institucional, as práticas discriminatórias instituídas terminam por receber uma condenação pública muito menor do que as realizadas sem intermédio do aparelho estatal, o que torna extremamente difícil atribuir a culpa dessas situações à atores específicos, já que, nesse contexto, o racismo se configura como uma racionalidade difusa, não se caracterizando, portanto, por meio de comportamentos explícitos e manifestos, mas por meio de estratégias instituídas sutis e camufladas. Por conta disso, o referido processo é denominado como racismo institucional (LÓPEZ, 2012).

Nesse cenário, passam a ser frequentes situações como as seguintes: tratamento diferenciado e desigual entre brancos e negros nas relações de trabalho; dificuldade de reconhecimento da competência de pessoas negras em cargos técnicos e de gestão; discriminação dos usuários em função do seu pertencimento racial; falta de conhecimento sobre diversidade e práticas culturais e religiosas; ausência de normas, práticas e comportamentos que estimulem a equidade; invisibilidade da diversidade e das desigualdades étnico-raciais nos diagnósticos e nos programas das secretarias, assim como na análise e interpretação de dados epidemiológicos na área da saúde (LÓPEZ, 2012) e, principalmente (no caso do estudo em questão), a falta de pesquisas sobre questões étnico-raciais em saúde, as quais podem variar desde a investigação de seus aspectos biológicos até a compreensão de elementos simbólicos-culturais, como as religiões de terreiros.

A partir disso, temos uma constatação: o racismo institucional hegemonicamente atravessa o campo da saúde e nós, por estarmos circunscritos nesses circuitos, não estamos alheios a esse processo, de forma que muitos dos anseios que carregávamos antes da nossa entrada nos terreiros enquanto pesquisadores reproduziam esse fenômeno, como por exemplo, o medo do desconhecido, o qual estava materializado principalmente por meio das cerimônias religiosas de culto às divindades e de oferta do cuidado em saúde, as quais funcionavam a partir de racionalidades com as quais não estávamos habituados.

Devemos também ressaltar que as comunidades em que se localizavam os terreiros de Umbanda, e consequentemente as ESF, estavam localizadas em regiões em situação de vulnerabilidade social, sendo caracterizadas por um acesso mínimo da população à direitos considerados fundamentais, tais como saúde, educação, assistência, lazer, moradia, infraestrutura urbana e transporte público de qualidade.

Tais questões se acentuavam ainda mais se levarmos em consideração que as religiões de matrizes africanas historicamente têm funcionado durante o período da noite e da madrugada, momentos nos quais éramos atravessados pelas construções sociais em torno da violência e do grau de periculosidade em bairros populares. O que podemos perceber, portanto, é que os conhecimentos e as práticas hegemônicas da Saúde pouco têm dialogado com os aspectos sociais, econômicos, políticos e culturais das classes populares por vieses que não remetam ao higienismo, ao campanhismo e ao preventivismo, conforme aponta Cotta e colaboradores (2007) ao discorrerem sobre a formação dos profissionais da saúde em cenário de pobreza, injustiça e desigualdade social.

Nesse sentido, quando tais atores sociais são convidados a se inserir na realidade desses povos, existem medos, reticências e estranhamentos, conforme o que experenciamos em determinados momentos. Apesar dessa situação ter se desenrolado no contexto específico 
de nossa investigação, não nos espantaria caso ela também acontecesse com muitos dos acadêmicos e profissionais de saúde que se proponham em realizar pesquisas em terreiros de Umbanda, principalmente se levarmos em consideração que tais condições são características de boa parte dos municípios brasileiros, de modo que tais sujeitos podem acabar se deparando com esses mesmos obstáculos.

\section{Considerações finais}

A partir do presente texto, foi possível percebermos uma indissociabilidade entre o ato de realizar uma guia (artefato religioso) e o de pesquisar em terreiros de Umbanda. Expliquemos o porquê. Ao fazer o objeto sagrado em questão, você cuidadosamente vai colocando uma conta por vez. O processo não acontece por acaso. Você já acompanhou outras pessoas fazendo essa mesma atividade.

Além disso, uma linha irá lhe guiar (e é nela que cada pedrinha será colocada): a mesma não é estática. Pelo contrário! É viva. Tem movimento. Dobra-se quando você precisa. E de miçanga em miçanga, temos o produto final, o qual não é mais apenas um amontoado de contas: o resultado é um artefato sagrado condensador de forças e com um imenso significado. $\mathrm{O}$ mesmo acontece numa atividade de pesquisa em saúde nos terreiros.

As contas utilizadas em um estudo geralmente são encontradas nos mais distintos lugares, tais como artigos, livros, manuais ou por meio das nossas próprias experiências. $\mathrm{E}$ assim como acontece com os povos de terreiros, você também vai colando umas pedrinhas às outras por meio da linha que lhe norteia: a de sua perspectiva ético-política. Ela que juntará todas as contas e fará com que investiguemos processos sociais, econômicos, políticos e culturais.

A partir desse pressuposto que lhe direciona, você vai escolhendo as contas com as quais trabalhará: campo problemático, objetivos, tipo de estudo, participantes, instrumentos, procedimentos e assim por diante. Depois de muita labuta, o artefato fica pronto. Ele não se transformou em um mero amontoado de miçangas. Como esperávamos, o seu esforço resultou num produto de grande valia e que lhe acompanhará durante todo seu estudo.

Entretanto, engana-se quem pensa que numa atividade de pesquisa as contas seriam blocos estanques e separados. Vejamos novamente como acontece o ato de fazer uma guia. Uma vez que uma miçanga é escolhida e colocada junto às demais, ela não pode ser tirada de modo fácil e rápido, principalmente quando outras contas também já foram inseridas $a$ posteriori. Qualquer tentativa de removê-la resultará em perdas que ocasionará a retirada de outras miçangas. No pesquisar em saúde nos terreiros, o processo se configura à semelhança da confecção de uma guia, principalmente, no que se refere ao náilon ou fio (tecido de palha de buriti, de carnaúba ou tucum). Não obstante, à diferença da guia (fundamento religioso), a guia do pesquisador, no que se refere às estratégias (contas), pode-se abrir mão de uma conta (abdicar de algum elemento) que não dará conta de um analisador que emerge no processo de pesquisa para inserir outras contas, ferramentas-conceitos que se fizerem necessários para 
compor o campo de análise e o campo de intervenção, sem abrir mão da guia, ou seja, da perspectiva ético-política.

Por fim, foi possível perceber que o campo da saúde historicamente tem possibilitado pouca participação dos povos de terreiros tanto das suas práticas de planejamento, implementação, avaliação e gestão do cuidado em saúde como também das suas atividades de pesquisa, o que revela a importância do referido estudo, já que no campo da Psicologia e Saúde Coletiva, a referida investigação contribuiu para se pensar estratégias de pesquisa que dialogassem com as ancestralidades, com os saberes e práticas populares e, principalmente, com as religiões de matrizes africanas, apostando na necessidade de pensarmos em diretrizes investigativas a partir de perspectivas interventivas e participativas.

\section{Referências}

ADORNO, Sergio. História e Desventura: o $3^{\circ}$ Programa Nacional de Direitos Humanos.

Novos Estudos - CEBRAP, n. 6, p. 5-20, mar. 2010.

BAREMBLITT, Gregório. Compêndio de análise institucional e outras correntes: teoria e prática. 5. ed. Belo Horizonte, MG: Instituto Félix Guattari, 2002.

BARROS, Marcelo. O candomblé bem explicado (Nações Bantu, Iorubá e Fon). Rio de Janeiro: CIP-BRASIL, 2009.

BRASIL. Presidência da República. Casa Civil. Subchefia para Assuntos Jurídicos. Lei no 8.080, de 19 de setembro de 1990. Brasília: Diário Oficial da República Federativa do Brasil, 1990a.

BRASIL. Presidência da República. Casa Civil. Subchefia para Assuntos Jurídicos. Lei no 8.142, de 28 de dezembro de 1990. Brasília: Diário Oficial da República Federativa do Brasil, 1990b.

BRASIL. Sistema Nações Unidas. Subsídios para o debate sobre a política nacional de saúde da população negra: uma questão de equidade. Brasília: Nações Unidas, 2001.

BRASIL. Presidência da República. Casa Civil. Subchefia de Assuntos Jurídicos. Decreto no 6.872, de 4 de junho de 2009. Brasília: Diário Oficial da República Federativa do Brasil, 2009.

BRASIL. Presidência da República. Casa Civil. Subchefia de Assuntos Jurídicos. Lei no 12.228, de 20 de julho de 2010. Brasília: Diário Oficial da República Federativa do Brasil, 2010 .

BRASIL. Ministério da Saúde. Secretaria de Gestão Estratégica e Participativa. Departamento de Apoio à Gestão Participativa. Política de saúde integral da população negra: uma política para o SUS. 2. ed. Brasília: Editora do Ministério da Saúde, 2013a. 
BRASIL. Ministério da Saúde. Portaria no 2.761, de 19 de novembro de 2013. Brasília: Diário Oficial da República Federativa do Brasil, 2013b.

CASTRO, Yeda Pessoa. O tráfico transatlântico e a distribuição da população negra escravizada no Brasil Colônia. Revista Digital Africanias, v. 12, p. 1-12, 2012.

COTTA, Rosângela Minardi Mitre et al. Pobreza, Injustiça e Desigualdade Social: Repensando a formação de profissionais de saúde. Revista Brasileira de Educação Médica. Rio de Janeiro, v. 31, n. 3, p. 278-286, dez. 2007.

FREITAS, Madalena Dias Silva. Refletir sobre a História do Negro no Brasil: Uma Resposta ao Racismo. In: CONGRESSO DE EDUCAÇÃO, 2., 2012, Iporá, GO. [Anais do...] Iporá, GO: Universidade Estadual de Goiás, 2012.

GOMES, Márcia Constância Pinto Aderne. Projeto: Ylê ayié yaya ilera (Saúde plena na casa desta existência): equidade e integralidade em saúde para a comunidade religiosa afro-

brasileira. Interface: Comunicação Saúde Educação. Botucatu, v. 14, n. 34, p. 663-672, set. 2010 .

KALCKMANN, Suzana et al. Racismo Institucional: um desafio para a equidade no SUS?. Saúde \& Sociedade. São Paulo, v. 16, n. 2, p. 146-155, ago. 2007.

L'ABBATE, Solange. A análise institucional e a saúde coletiva. Ciência \& Saúde Coletiva. Rio de Janeiro, v. 8, n. 1, p. 265-274, 2003.

L'ABBATE, Solange. Análise Institucional e Saúde Coletiva: uma articulação em processo. In: L’ABBATE, Solange; MOURÃO, Lúcia Cardoso; PEZZATO, Luciane Maria (Org.). Análise Institucional e Saúde Coletiva. São Paulo: HUCITEC Editora, 2013. p. 31-90.

LAGES, Sônia Regina Corrêa. Saúde da população negra: A religiosidade afro-brasileira e a saúde pública. Psicologia Argumento. Curitiba, v. 30, n. 69, p. 401-410, abr./jun. 2012.

LÓPEZ, Laura Cecilia. O conceito de racismo institucional: aplicações no campo da saúde. Interface - Educação, Saúde e Educação. Botucatu, SP, v. 16, n. 40, p. 121-134, jan./mar. 2012.

LOURAU, René. A Análise Institucional. Tradução de Mariano Ferreira. Petrópolis: Vozes, 1975.

LOURAU, René. O instituinte contra o instituído. In: ALTOÉ, Sônia (Org.). René Lourau: Analista Institucional em tempo integral. São Paulo: HUCITEC Editora, 2004. p. 47-65.

MELLO, Márcio Luiz; OLIVEIRA, Simone Santos. Saúde, religião e cultura: um diálogo a partir das práticas afro-brasileiras. Saúde \& Sociedade. São Paulo, v. 22, n. 4, p. 1024-1035, dez. 2013.

MOTA, Clarice Santos; TRAD, Leny Alves Bomfim. A gente vive pra cuidar da população: estratégias de cuidado e sentidos para saúde, doença e cura em terreiros de Candomblé.

Saúde e Sociedade. São Paulo, v. 20, n. 2, p. 325-337, jun. 2011. 
RIBEIRO, Josenilda Oliveira. Sincretismo Religioso no Brasil: Uma Análise Histórica das Transformações no Catolicismo, Evangelismo, Candomblé e Espiritismo. Trabalho de Conclusão de Curso (Graduação em Serviço Social) - Universidade Federal de Pernambuco. Recife, Pernambuco, 2012.

RIOS, Luis Felipe et al. Axé, práticas corporais e Aids nas religiões africanistas do Recife, Brasil. Ciência \& Saúde Coletiva. Rio de Janeiro, v. 18, n. 12, p. 3653-3662, dez. 2013.

SAMPAIO, Juliana et al. Limites e potencialidades das rodas de conversa no cuidado em saúde: uma experiência com jovens no sertão pernambucano. Interface. Botucatu, SP, v. 18, supl. 2, p. 1299-1312, 2014.

SILVA, Rafael Afonso; FERNANDEZ, Juan Carlos Aneiros; SACARDO, Daniele Pompei. Para uma "ecologia de saberes" em saúde: Um convite dos terreiros ao diálogo. Interface. Botucatu, SP, v. 21, n. 63, p. 921-931, out./dez. 2017.

SILVEIRA, Hendrix Alessandro Anzorena. Tradições de matriz africana e saúde: o cuidar nos terreiros. Identidade! São Leopoldo, v. 19, n. 2, p. 75-88, jul./dez. 2014.

SPAGNOL, Carla Aparecida et al. Dispositif socianalytique: instrument d'intervention et de collecte de données en recherche qualitative en soins infirmiers. Recherche en soins infirmiers, n. 124, p. 6-15, feb. 2016.

\section{Notas}

\footnotetext{
' São chamados de guias os colares usados pelos médiuns durante as sessões e giras e também utilizadas pelos filhos da casa representando os seus guias (Orixás), variando a cor conforme a Linha na qual o espírito atua.

ii $\mathrm{Na}$ sociedade colonial brasileira, o "capitão do mato" era a figura responsável por capturar os negros fugitivos das fazendas ou feitorias.

iii Aprova o Plano Nacional de Promoção da Igualdade Racial (PLANAPIR) e institui o seu Comitê de Articulação e Monitoramento (BRASIL, 2009).

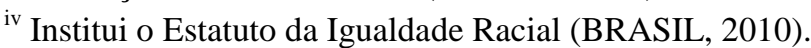

\section{Agradecimentos}

O presente trabalho foi realizado com apoio da Coordenação de Aperfeiçoamento de Pessoal de Nível Superior - Brasil (CAPES) - Código de Financiamento 001. 